\title{
Impactos da ocupação urbana na permeabilidade do solo: o caso de uma área de urbanização consolidada em Campina Grande - PB
}

\author{
Impacts of the disordered land occupancy: a study about \\ an urban consolidated area in Campina Grande - PB
}

\begin{abstract}
Karla Azevedo Santos', lana Alexandra Alves Rufino², Mauro Normando Macêdo Barros Filho ${ }^{3}$
\end{abstract}
\begin{abstract}
RESUMO
A ocupação urbana intensa e não planejada acarreta problemas diretos à população. Um desses problemas éa diminuição do índice de permeabilidade do solo gerada pela pavimentação crescente que sempre acompanha o desenvolvimento urbano de uma região. Em consequência, o sistema de drenagem pode sofrer sobrecargas uma vez que a capacidade de infiltração do solo é alterada e a pavimentação aumenta a velocidade de escoamento e as vazões de pico. Este trabalho apresenta uma análise integrada da dinâmica do uso do solo ao longo de 32 anos e do comportamento do sistema de microdrenagem urbana para o cenário atual de ocupação dos bairros Catolé e Sandra Cavalcante, em Campina Grande (PB). Verifica-se a deficiência do sistema de microdrenagem em não acompanhar o acelerado crescimento da região, acarretando em pontos de alagamento que geram prejuízos e desconfortos à população em períodos de chuva mais concentrada.
\end{abstract}

Palavras-chave: expansão urbana; planejamento urbano; impermeabilização do solo; microdrenagem.

\begin{abstract}
The intense and unplanned urban occupation entails direct problems to the population. One of these problems is the decrease in the permeability index of soil generated by increasing paving that always accompanies the urban development of a region. As a result, the drainage system may experience overloads, once the infiltration capacity of the soil is changed and the paving increases the flow rate and the peak flows. This paper presents an integrated analysis of land use dynamics over the course of 32 years and the behavior of the urban micro-drainage system to the current scenario of occupation of Catolé and Sandra Cavalcante neighborhoods, in Campina Grande, PB. It verifies the disability of the micro-drainage system to accompany the accelerated growth of the region, leading in points of flooding that generate losses and discomforts to the population in more concentrated rain periods.
\end{abstract}

Keywords: urban sprawl; urban planning; paving increase; micro-drainage.

\section{INTRODUÇÃO}

O crescimento acelerado da população urbana em cidades de países em desenvolvimento é um tema recorrente (ALMEIDA, 2003; KAUFFMANN, 2003; MARICATO, 2003; POLIDORI, 2005; ROLNIK et al., 2011; SOUZA, 2009). Tal fato acarreta uma série de impactos - ambientais, sociais, econômicos e culturais - que interferem diretamente no cotidiano da população. De acordo com Cohen (2006), no começo do século XX, apenas 16 cidades no mundo e, a grande maioria delas, em países industrialmente desenvolvidos, continham 1 milhão de habitantes ou mais. Ainda segundo Cohen (2006), no início deste século, quase 400 cidades possuíam essa quantidade de habitantes, e, aproximadamente, $70 \%$ delas estavam em países em desenvolvimento. Um exemplo é a cidade de Dakar, hoje considerada a nona maior cidade em aglomerados urbanos, com 12,5 milhões de habitantes e que, na década de 1950, possuía apenas 417 mil habitantes, segundo o United Nations Human Settlements Programme (UN-HABITAT, 2004). No Brasil, o processo de ocupação urbana não apresentou grande evolução até o século XIX, começando a apresentar significativo crescimento a partir da segunda metade do século XX (KAUFFMANN, 2003) com o incentivo à industrialização e à construção de uma infraestrutura industrial. Isso estimulou o movimento de migração do campo para a

口-

'Mestre em Engenharia Civil e Ambiental pela Universidade Federal de Campina Grande (UFCG) - Campina Grande (PB). Brasil.

2Professora adjunta da Unidade Acadêmica de Engenharia Civil da UFCG - Campina Grande (PB), Brasil.

${ }^{3}$ Professor adjunto da Unidade Acadêmica de Engenharia Civil da UFCG - Campina Grande (PB), Brasil.

Endereço para correspondência: Karla Azevedo Santos - Rua José Jesuíno de Brito, 49 - Quarenta - 58416-270 - Campina Grande (PB), Brasil - E-mail: azevedoarquiteta3@gmail.com Recebido em: 03/03/15 - Aceito em: 23/08/16 - Reg. ABES: 146661 
cidade, contribuindo para o aumento das regiões periféricas, que passaram a crescer mais do que os núcleos urbanos; o aumento da densidade populacional; a ocupação do solo; e a exclusão social (MARICATO, 2003). Para Kauffmann e Silva (2005), esse cenário reafirma a incapacidade da política e do planejamento urbanos de resolver, de forma eficiente, os impactos negativos da ação antrópica no meio ambiente.

Todavia, sabe-se que o crescimento da população e, em consequência, a expansão urbana, são processos naturais sobre os quais não se têm completo controle. Entretanto, o planejamento é imprescindível para a garantia da qualidade de vida da população, sobretudo, no tocante aos recursos hídricos. Os impactos sobre as águas urbanas, em geral, ficam atrelados ao forte adensamento urbano, além das questões climáticas e às práticas inconsequentes da população, como: o despejo de esgoto, sem tratamento, nos rios; os depósitos de resíduos sólidos, que contaminam as águas superficiais e subterrâneas; a ocupação do solo urbano sem controle do impacto sobre o sistema hídrico; dentre outras (TUCCI, 2008).

Para Polidori (2005), os encarregados dos planejamentos urbano e ambiental estão sendo desafiados, a cada dia mais, a integrar dados urbanos e dos ambientes naturais para compreender as cidades e planejar o seu futuro. A apropriação não planejada e desenfreada do solo urbano, além de causar danos ao meio ambiente por meio da ocupação de áreas de preservação pela população mais desfavorecida financeiramente, é um dos impactos que traz danos mais visíveis à população (GRANDE et al., 2014). Segundo Grande et al. (2014), a percepção dos riscos ambientais não é tão óbvia, sobretudo por aqueles que estão longe de tais problemas.

A ocupação do solo urbano sem planejamento tem como consequência, dentre outros impactos ambientais negativos: i) a sobrecarga no sistema de drenagem urbana por meio do aumento da impermeabilização do solo e da diminuição da infiltração; ii) a perda da cobertura vegetal por pavimentos impermeáveis, diminuindo a infiltração da água no solo e aumentando a sua quantidade e a sua velocidade de escoamento; iii) a escassez e a diminuição da qualidade dos recursos hídricos; iv) o acúmulo de resíduos sólidos nos elementos do sistema de drenagem (canais, bueiros, bocas de lobo, etc.), obstruindo-os e, com isso, ocasionando seus transbordamentos em períodos de chuva; e v) o aumento da densidade urbana em determinadas zonas, principalmente as consideradas de baixo valor especulativo imobiliário da cidade. Esse último é, entretanto, segundo Acioly e Davidson (2011), um assunto controverso que pode gerar impactos positivos e/ou negativos no desenvolvimento urbano, maximizando a infraestrutura de uma cidade ou, por outro lado, causando uma sobrecarga da mesma.

Esse contexto tem como alicerce o planejamento e a gestão urbanos, cujo papel fundamental é orientar a ocupação do solo a partir dos parâmetros urbanísticos (gabarito, afastamento, taxa de ocupação, coeficiente de aproveitamento, taxa de permeabilidade etc.), agregados ao zoneamento urbano. Esses parâmetros foram aprimorados com a Reforma Urbana (SOUZA, 2009). Ainda segundo Souza (2003), os Planos Diretores tiveram maior força entre os anos de 1980 e 1990, no Brasil. Para esse autor, a maneira como esses parâmetros condicionantes da ocupação são regulamentados e o uso que deles for feito é que mostrará se a reforma será benéfica ou maléfica para a cidade.

Diante desse contexto, foi escolhida a cidade de Campina Grande (PB) como estudo de caso, por se tratar de uma urbe em crescimento. Segundo dados do IBGE, em vinte anos, entre 1991 e 2010, a população aumentou de 307.468 para mais de 400.000 habitantes, respectivamente. Já entre os anos de 2007 a 2010, o aumento foi de quase 13 mil habitantes. É importante observar que esse crescimento vem sendo processado sem o adequado planejamento urbano.

Em períodos de chuva, observamos falhas no sistema de drenagem de muitos bairros da cidade, causando transtornos à população. Dentre esses bairros, escolheu-se Catolé e Sandra Cavalcante como objetos de estudo, por serem locais que apresentam altas densidades populacionais urbanas e que possuem uma intensa ocupação do solo urbano, com tendência à verticalização da forma de morar, com muitas superfícies impermeáveis, o que tem acarretado, em alguns pontos do bairro, em alagamentos frequentes após eventos chuvosos. Atrelado a isso, verificam-se a topografia plana da área (os dois bairros juntos configuram uma microbacia de drenagem) e falhas observadas no sistema de drenagem convencional.

Diante do exposto, este estudo tem como objetivo principal realizar uma análise integrada da drenagem e da dinâmica de ocupação do solo urbano nos bairros Catolé e Sandra Cavalcante, na cidade de Campina Grande (PB), visando a dar suporte à gestão municipal.

\section{MATERIAIS E MÉTODOS}

\section{Área de estudo}

A cidade de Campina Grande, no estado da Paraíba, representa um grande e promissor polo educacional, tecnológico e econômico. O município está localizado a $7^{\circ} 13^{\prime} 50^{\prime \prime}$ Sul e $35^{\circ} 52^{\prime} 52^{\prime \prime}$ Oeste de Greenwich; possui uma área territorial de $594,182 \mathrm{~km}^{2}$ e população estimada em 402.912 habitantes (IBGE, 2014). Sua densidade demográfica é de 678,10 habitantes por $\mathrm{km}^{2}$. Os bairros Catolé e Sandra Cavalcante (Figura 1A) encontram-se na Zona Sul da cidade apresentando, segundo dados do IBGE, densidades demográficas de 6.782 hab. $/ \mathrm{km}^{2}$ e 4.959 hab. $/ \mathrm{km}^{2}$, respectivamente, e estão inseridos na Bacia Hidrografia do Riacho do Prado (Figura 1B), 
que possui $37,15 \mathrm{~km}^{2}$ de área e abrange outros importantes bairros de Campina Grande, como: Liberdade, Cruzeiro, parte do Centro e José Pinheiro, além de outros municípios, como: Lagoa Seca, Puxinanã e Queimadas.

Apesar de predominantemente residenciais, os bairros abrigam equipamentos urbanos de grande porte, como: terminal interurbano de passageiros (rodoviária), shopping center, grandes escolas, igrejas, clubes, parque, dentre outros. Apesar de toda a infraestrutura presente, esses bairros têm sido notícia em jornais por sofrerem, de forma recorrente, inundações em diversas ruas (Figura 2) e, principalmente, em cruzamentos de vias importantes que apresentam alto volume de tráfego de veículos.

\section{A análise do espaço no tempo}

Foi realizada uma análise multitemporal da dinâmica de ocupação do espaço nos bairros Catolé e Sandra Cavalcante para os anos de 1982, 2011 e 2014. O fator relevante para a escolha das datas foi a disponibilidade de dados encontrados em pesquisas já realizadas (ARAÚJO, 2012; NÓBREGA, 2012), tendo em vista que a obtenção de dados de uso e ocupação do solo ainda é consideravelmente limitada. Por meio da digitalização e da vetorização de um mapa do ano de 1982, da consulta aos moradores e pesquisadores e também de uma ortoimagem desse ano fornecida pela Prefeitura Municipal de Campina Grande, tornou-se possível a quantificação das áreas ocupadas e desocupadas daquele período.

Para o ano de 2011, foram utilizados dados coletados por Araújo (2012) para o bairro do Catolé e, com auxílio do Google Earth, foi realizado o estudo de uso e ocupação no bairro Sandra Cavalcante. Uma ortoimagem do ano de 2010, também fornecida pela Prefeitura, contribuiu para que o estudo fosse realizado com mais fidelidade.

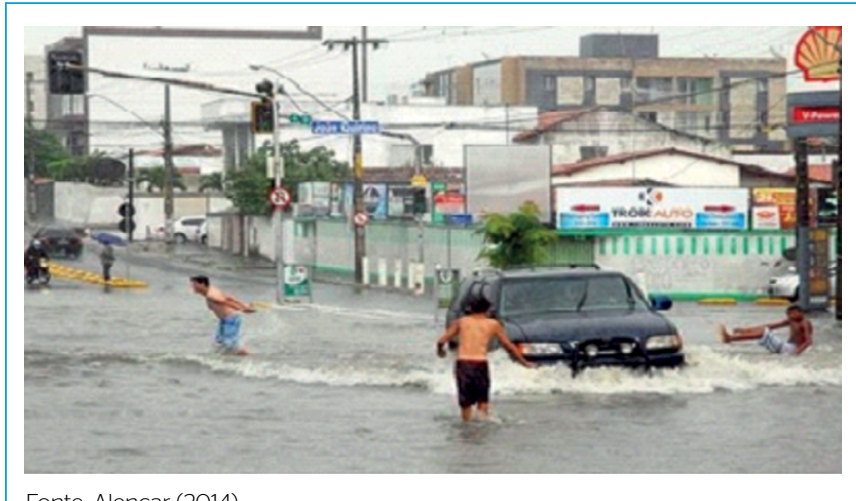

Fonte: Alencar (2014)

Figura 2 - Imagem de um cruzamento importante no bairro do Catolé após um evento chuvoso.

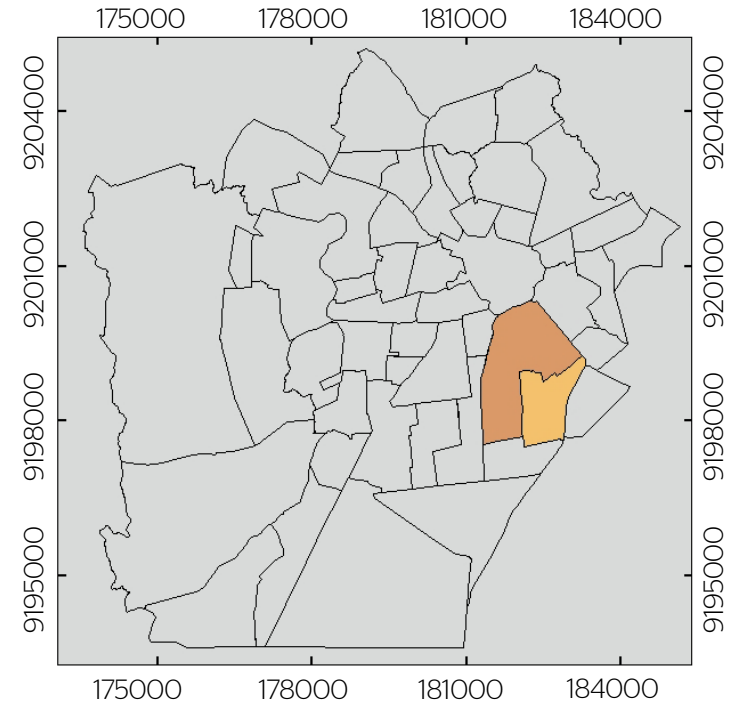

Localização dos bairros estudados

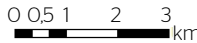

Limites de Bairros Catolé

Sandra Cavalcante

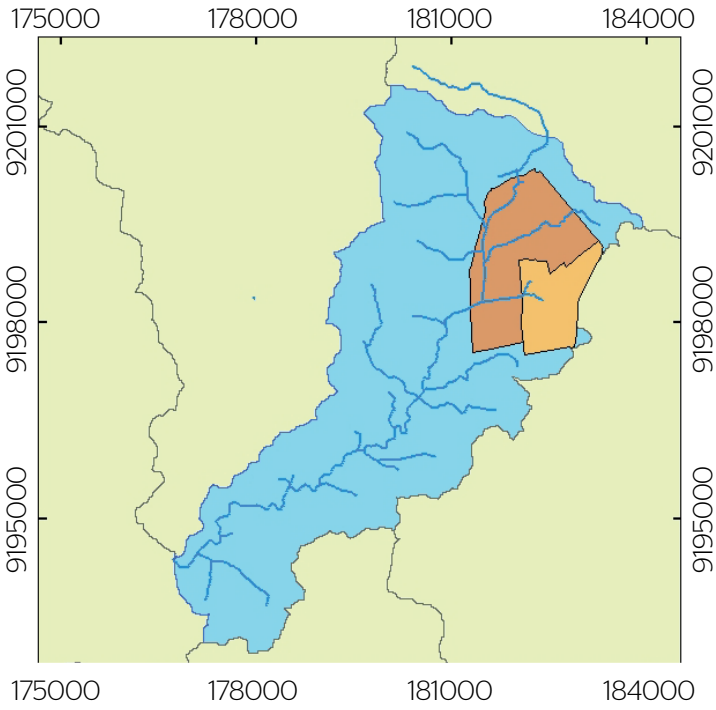

Bacia Hidrográfica do Riacho do Prado

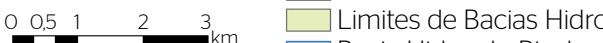
Bacia Hidro. do Riacho do Prado 
Para o ano de 2014, foram utilizadas imagens do Street View, ferramenta do Google Earth, além de visitas de campo (SANTOS, 2014). Todos os dados foram digitalizados e editados utilizando o software desktop ArcGIS 10.2.2 ${ }^{\circledR}$ (Esri).

\section{A quantificação da área impermeável}

A porcentagem de área impermeável em cada quadra é um dos dados de entrada do modelo hidrológico utilizado. Então, a partir da elaboração dos cenários, foi possível estimar a quantificação da impermeabilidade do solo por meio de um único método para os três períodos. Identificou-se a implantação das edificações nos lotes, e fez-se a diferença entre área construída e superfície natural, obtendo-se a porcentagem estimada da área impermeável em cada lote. Para o ano de 1982, o qual não possuía dados oficiais de ocupação do solo da época, tomou-se por base um mapa de edificações feito em CAD, elaborado por pesquisadores em estudo prévio, por meio de relatos de moradores antigos do local. A partir da ortoimagem do ano de 2010 fornecida pela Prefeitura, a qual foi editada por meio do software desktop ArcGis, destacou-se as edificações em cada lote e, posteriormente, calculou-se a quantificação da impermeabilidade desse cenário. Para o período de 2014, foi utilizada uma imagem de satélite desse ano para que fosse feita a atualização da porcentagem obtida para o ano de 2011.

\section{A simulação hidrológica}

Para essa simulação, as quadras foram consideradas sub-bacias, que é a terminologia usada no modelo de simulação para cada unidade de área em que será analisado o escoamento durante e depois do evento chuvoso. Foi utilizado o modelo calibrado por Nóbrega (2012), usando o software Storm Water Management Model SWMM (ROSSMAN, 2010). A calibração foi realizada devido à necessidade de encontrar os valores estimados de capacidade de armazenamento em depressões em superfícies impermeáveis (DI) e permeáveis (DP). Para tanto, foram considerados os intervalos sugeridos no Manual do Usuário do SWMM (ROSSMAN, 2010), apresentados na Tabela 1. Foi utilizado o método de tentativa e erro, com ajuste manual dos parâmetros de entrada do programa SWMM para caracterização das sub-bacias (Tabela 2), até chegar a um valor médio de DI e DP para aquela região. O resultado está apresentado na Tabela 3. Também foram estimadas, pelo mesmo método, as áreas impermeáveis não conectadas (AINC). Ainda para a calibração, foram considerados os tipos de solo predominantes na região com seus respectivos coeficientes de Manning (Tabela 4) e 11 eventos chuvosos ocorridos, entre julho de 2007 e agosto de 2011, para tempos de retorno de 1, 2 e 5 anos, dentre os quais foram escolhidos os 8 eventos com maior volume de precipitação e que geraram inundações no local (Tabela 5). Os valores médios de DI,
DP e AINC, obtidos por Nóbrega (2012) na calibração, foram utilizados para todos os tipos de solos observados no local.

A partir do estudo de ocupação do solo, da quantificação da impermeabilização em cada quadra e do conhecimento dos

Tabela 1 - Intervalos de capacidade de armazenamento em superfícies, sugeridos pelo Manual do Usuário do SWMM.

\begin{tabular}{c|c}
\multicolumn{2}{|c}{ Intervalos de valores DI e DP $(\mathrm{mm})$} \\
DI & $1,27-2,54$ \\
\hline DP & $2,54-5,08$ \\
\hline
\end{tabular}

Fonte: Rossman (2010).

Tabela 2 - Parâmetros de entrada do programa SWMM.

\begin{tabular}{l|c|c}
$\begin{array}{l}\text { Parâmetros para caracterização } \\
\text { das sub-bacias }\end{array}$ & Sigla & Unidade \\
\hline Area da Sub-bacia & A & ac \\
\hline Largura da Sub-bacia & W & $\mathrm{ft}$ \\
\hline Declividade da Sub-bacia & $\mathrm{S}$ & $\%$ \\
\hline Areas impermeáveis & $\mathrm{Al}$ & $\%$ \\
\hline $\begin{array}{l}\text { Coeficiente de Rugosidade de Manning - } \\
\text { Superfícies Impermeáveis }\end{array}$ & $\mathrm{NI}$ & - \\
\hline $\begin{array}{l}\text { Coeficiente de Rugosidade de Manning - } \\
\text { Superfícies Permeáveis }\end{array}$ & $\mathrm{NP}$ & - \\
\hline $\begin{array}{l}\text { Capacidade de Armazenamento em } \\
\text { Depressões - Superfícies Impermeáveis }\end{array}$ & $\mathrm{DI}$ & $\mathrm{In}$ \\
\hline $\begin{array}{l}\text { Capacidade de Armazenamento em } \\
\text { Depressões - Superfícies Permeáveis }\end{array}$ & DP & In \\
\hline Areas Impermeáveis Não-conectadas & AINC & $\%$ \\
\hline
\end{tabular}

Tabela 3 - Resultado da calibração realizada por Nóbrega (2012).

\begin{tabular}{l|c|c}
\multicolumn{3}{|c}{ Parâmetros calibrados } \\
$\begin{array}{l}\text { Capacidade de } \\
\text { armazenamento } \\
\text { em depressões } \\
\text { para superfícies } \\
\text { impermeáveis (DI) }\end{array}$ & $\begin{array}{c}\text { Capacidade de } \\
\text { armazenamento } \\
\text { em depressões } \\
\text { para superfícies } \\
\text { permeáveis (DP) }\end{array}$ & $\begin{array}{c}\text { Areas impermeáveis } \\
\text { não conectadas } \\
\text { (AINC) }\end{array}$ \\
\hline $1,91 \mathrm{~mm}$ & $5,08 \mathrm{~mm}$ & $10 \%$ \\
\hline
\end{tabular}

Fonte: adaptado de Nóbrega (2012)

Tabela 4 - Coeficientes de Manning utilizados na simulação.

\begin{tabular}{l|c}
\multicolumn{2}{c}{ Coeficiente de rugosidade de mannig } \\
\hline Asfalto liso & Coeficiente \\
\hline Argila & 0,011 \\
\hline Superfície cimentada & 0,015 \\
\hline Solos com vegetação natural & 0,024 \\
\hline
\end{tabular}

Fonte: Chow (1959). 
dados de intensidade, duração e frequência das chuvas (Figura 3), foi realizada a simulação hidrológica no SWMM para o ano de 2014. A Figura 3 apresenta um dos outputs do modelo hidrológico. Segundo esse gráfico, a intensidade da chuva para essas duração e frequência, foi de, aproximadamente, $40,00 \mathrm{~mm} / \mathrm{h}$. A simulação hidrológica gerou mapas de inundação, apresentados nos resultados, que possibilitaram a análise das áreas mais sensíveis a alagamentos na região.

\section{RESULTADOS E DISCUSSÃO}

A partir dos mapas de uso e ocupação do solo, gerados para a área de estudo, foi possível analisar o acelerado processo de ocupação que ocorreu nessa área (Figuras 4, 5 e 6). A partir desse mapeamento, foi quantificado o percentual de área permeável e impermeável dos bairros Catolé e Sandra Cavalcante (Figura 7), como também o significativo processo de verticalização das duas áreas.

Tabela 5 - Data dos eventos utilizados para a calibração do modelo.

\begin{tabular}{c} 
Data de ocorrência dos eventos chuvosos \\
\hline 18 de março de 2008 \\
\hline 25 de março de 2008 \\
\hline 20 de fevereiro de 2009 \\
\hline 11 de abril de 2009 \\
\hline O1 de março de 2011 \\
\hline O3 de março de 2011 \\
\hline 4 de maio de 2011 \\
\hline 17 de julho de 2011
\end{tabular}

Fonte: adaptado de Nóbrega (2012).

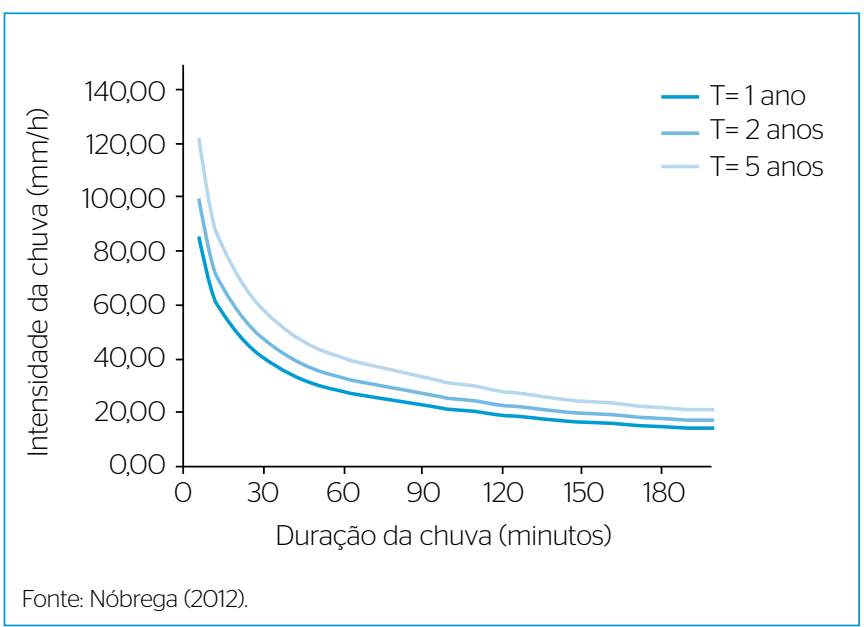

Figura 3 - Gráfico de intensidade x duração das chuvas para os tempos de retorno.
Observa-se que, apesar de as diferenças entre os anos de 2011 e 2014 não serem tão evidentes nos mapas, o processo de verticalização foi acelerado nesse intervalo de tempo. Em 2011, existiam 1.532 domicílios tipo apartamento na região, subindo para 1.804 , em 2014 (SANTOS, 2014). Esse aumento contribuiu para uma maior impermeabilização do solo, visto que as edificações multifamiliares aproveitaram mais o terreno (inclusive o subsolo) para área construída, reservando cada vez menos espaço para áreas verdes naturais.

Tomando-se como base o Plano Diretor (ESTADO DA PARAÍBA, 2006), observa-se que os dois bairros se encontram na Zona de Recuperação Urbana (Figura 8), que se caracteriza "pelo uso predominantemente residencial, carência de infraestrutura e equipamentos públicos, incidência de loteamentos irregulares e núcleos habitacionais de baixa renda" (Lei Complementar No 003, de 9 de outubro de 2006 - Plano Diretor Municipal - ESTADO DA PARAÍBA, 2006).

Segundo o Código de Obras do Município (ESTADO DA PARAÍBA, 2003), os bairros apresentam Taxa de Ocupação e Índice

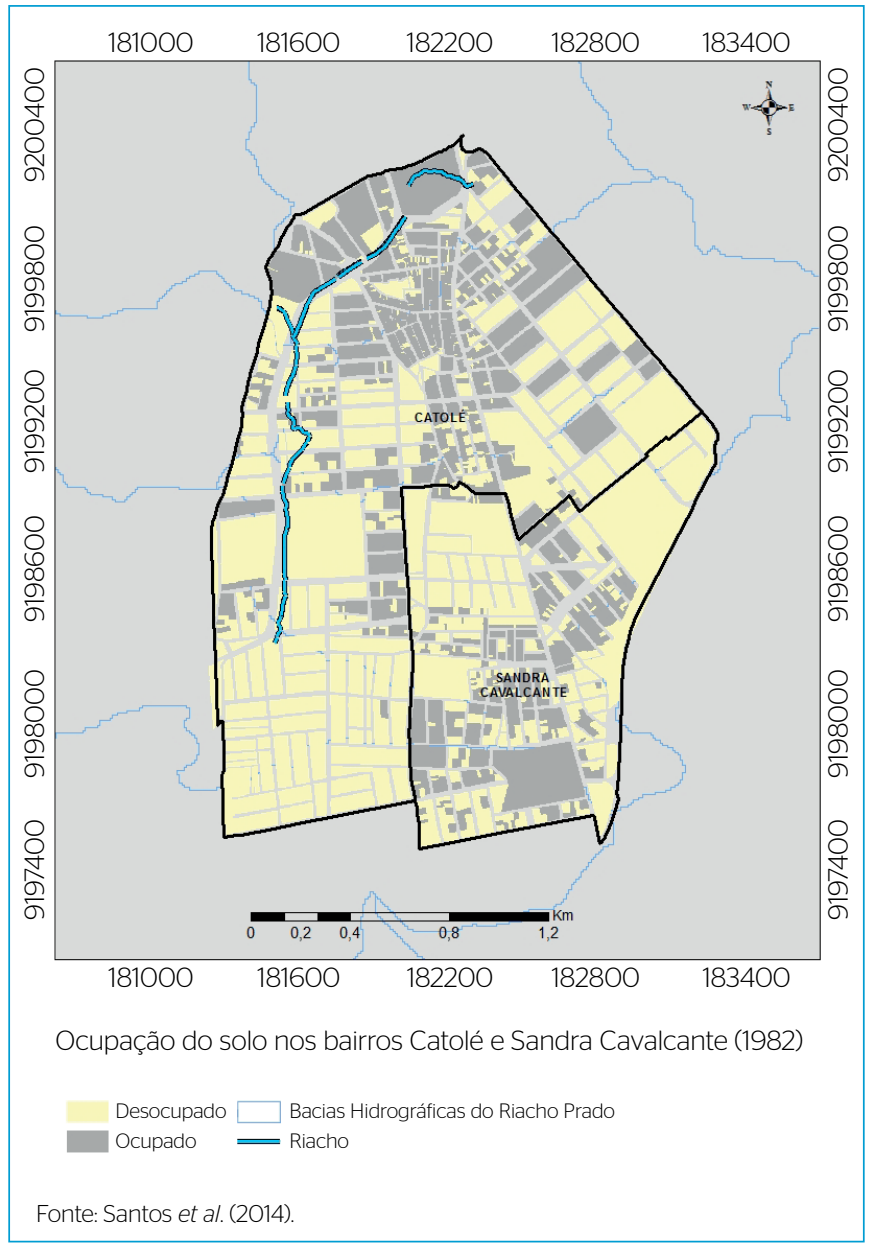

Figura 4 - Ocupação do solo dos bairros Catolé e Sandra Cavalcante para o ano de 1982 
de Aproveitamento (ou Coeficiente de Aproveitamento) máximos de acordo com a Tabela 6

Diante dos parâmetros urbanísticos e do zoneamento urbano, verificou-se que a legislação urbana, que fixa $60 \%$ de área ocupada para lotes residenciais e 75\% para lotes com outros usos (ver Tabela 3), não foi seguida nos bairros, tendo em vista que existem quadras com mais de $90 \%$ de percentual impermeável.

Foi gerado um mapa de inundação, para a situação atual (Figura 9), referente a uma chuva de 60 minutos com tempo de retorno de 5 anos, possibilitando a observação do comportamento do sistema de drenagem atual.

No mapa de inundação da Figura 9, observa-se que, logo após a ocorrência de chuva, 253 das 272 sub-bacias, apresentaram escoamento superficial com lâmina superior a $12,70 \mathrm{~mm}$; 16 sub-bacias apresentaram escoamento superficial entre 2,55 mm e 1,27 mm; uma sub-bacia apresentou lâmina entre 1,27 a 0,25 mm e apenas duas sub-bacias apresentaram lâmina de escoamento superficial inferior a $0,25 \mathrm{~mm}$ logo após a ocorrência de chuva.

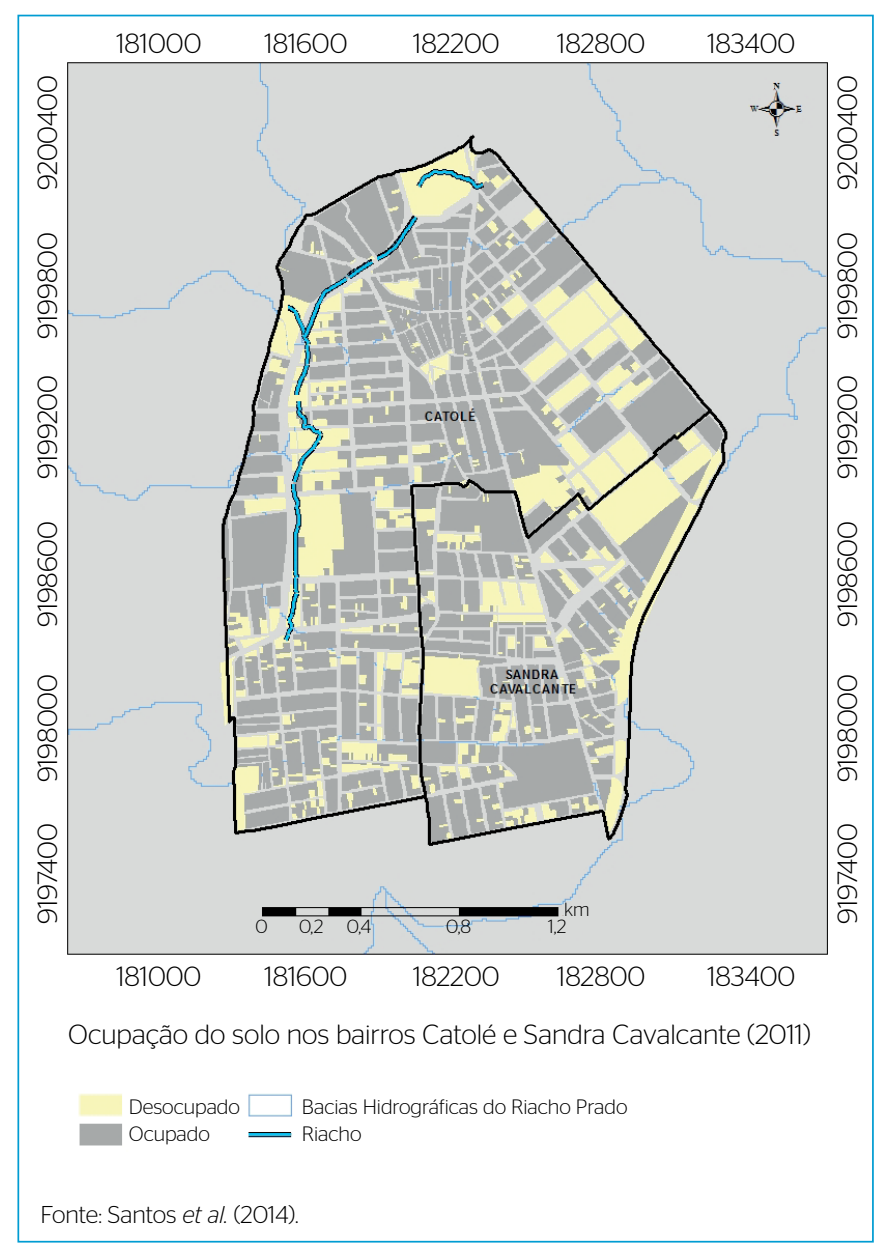

Figura 5 - Ocupação do solo dos bairros Catolé e Sandra Cavalcante para o ano de 2011.
Depois de 60 minutos da ocorrência de chuva, foi gerado um novo output mostrando a recuperação da bacia após evento chuvoso (Figura 10). Esse resultado mostra que, após esse período de recuperação, 29 sub-bacias ainda apresentaram escoamento superficial com lâmina superior a $12,77 \mathrm{~mm}$.

Por meio de uma validação com dados de campo, foi possível destacar alguns pontos dentre aqueles que apresentaram lâmina de escoamento superior a $12,70 \mathrm{~mm}$. Ao sul do bairro do Catolé, onde são verificados pontos de alagamento após um período de $60 \mathrm{minu}$ tos de recuperação da bacia, observa-se a presença de vias que ainda não foram pavimentadas e, consequentemente, o sistema de drenagem inexistente (Figura 11).

No destaque do bairro Sandra Cavalcante (Figura 12A), observou-se que a concentração de áreas alagadas é agravada pela condição topográfica. Sendo esse o ponto mais baixo do bairro, a tendência é que a água escoe naturalmente para o local. Portanto, faz-se necessário uma maior atenção no sistema de drenagem dessa região.

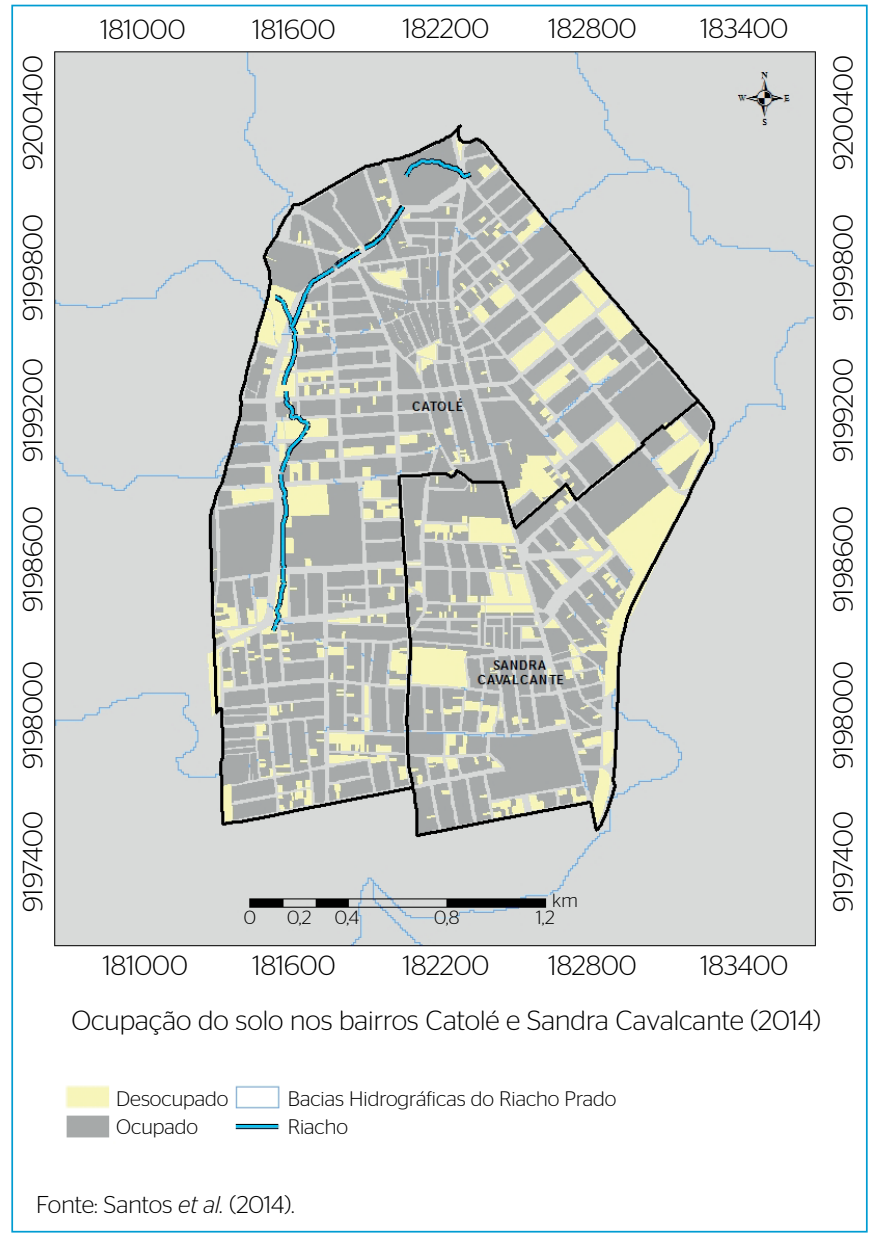

Figura 6 - Ocupação do solo dos bairros Catolé e Sandra Cavalcante para o ano de 2014. 
口

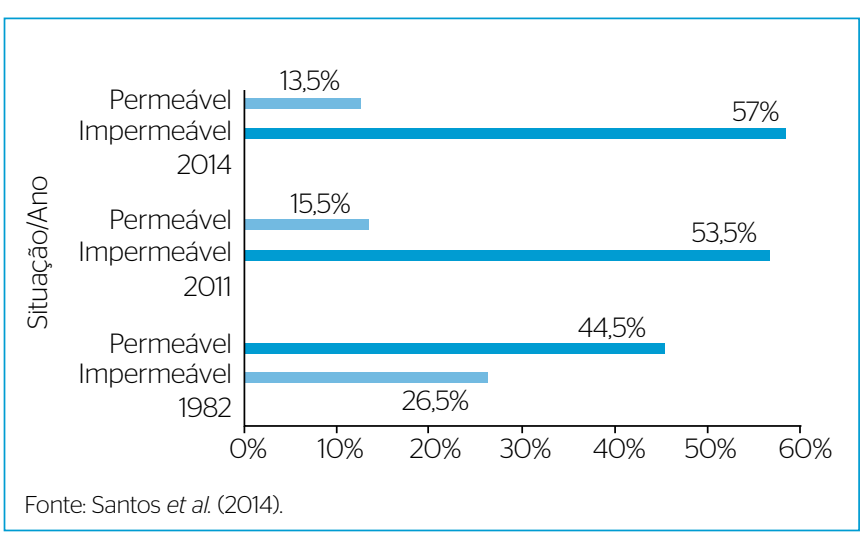

Figura 7 - Situação dos bairros em relação à porcentagem de área permeável e impermeável, nos anos de 1982, 2010 e 2014.

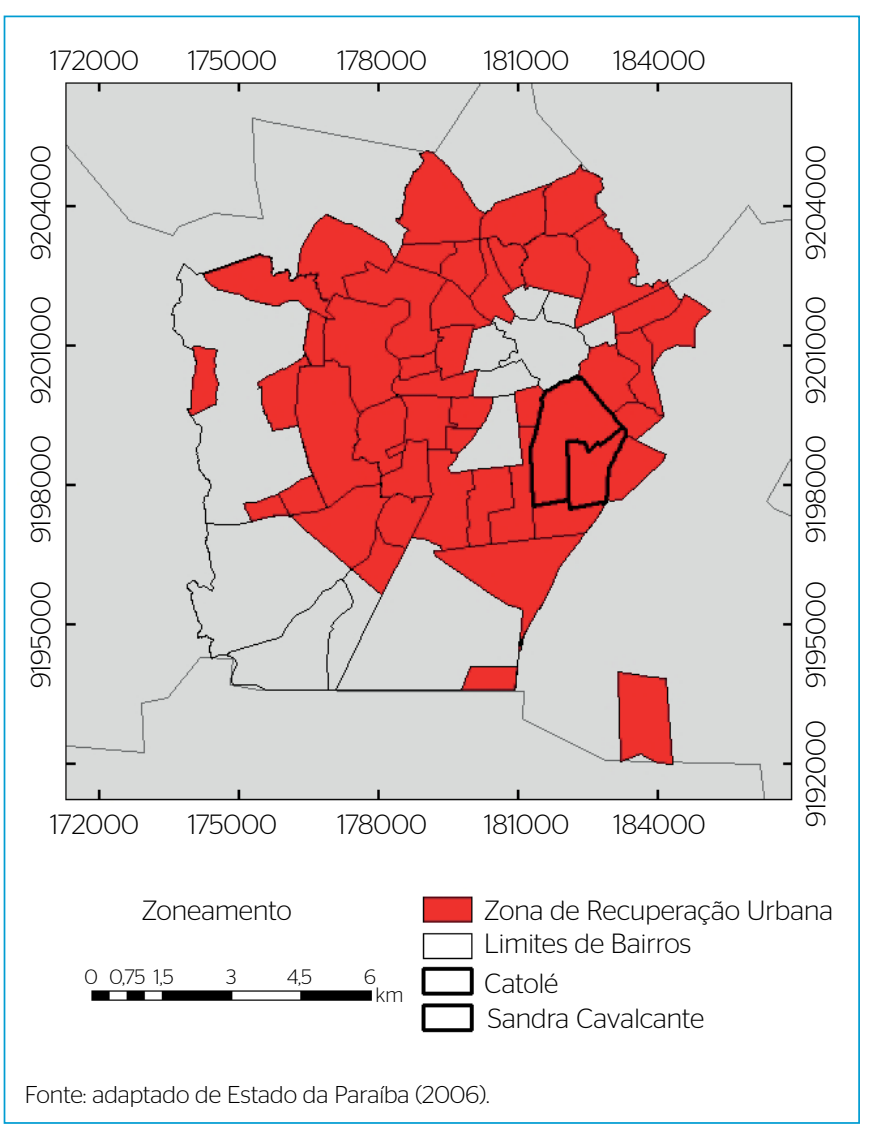

Figura 8 - Bairros Catolé e Sandra Cavalcante inseridos na Zona de Recuperação Urbana, segundo o Plano Diretor (2006).

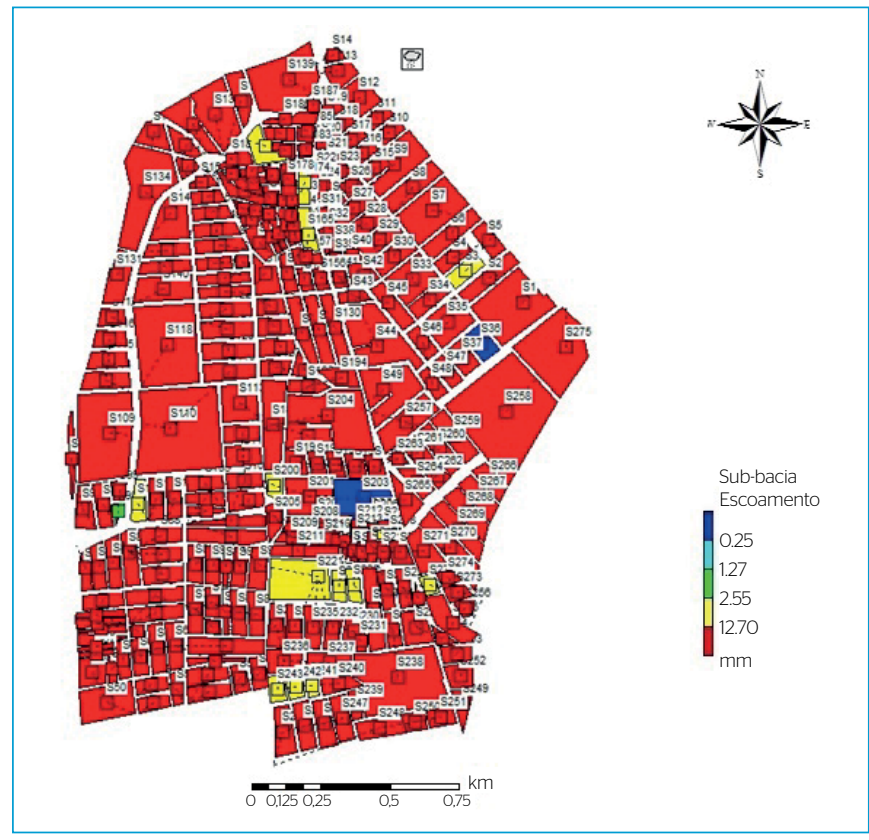

Figura 9 - Mapa de inundação para intensidade de chuva de 40,00mm/h com duração de 60 minutos e tempo de retorno de 05 anos.

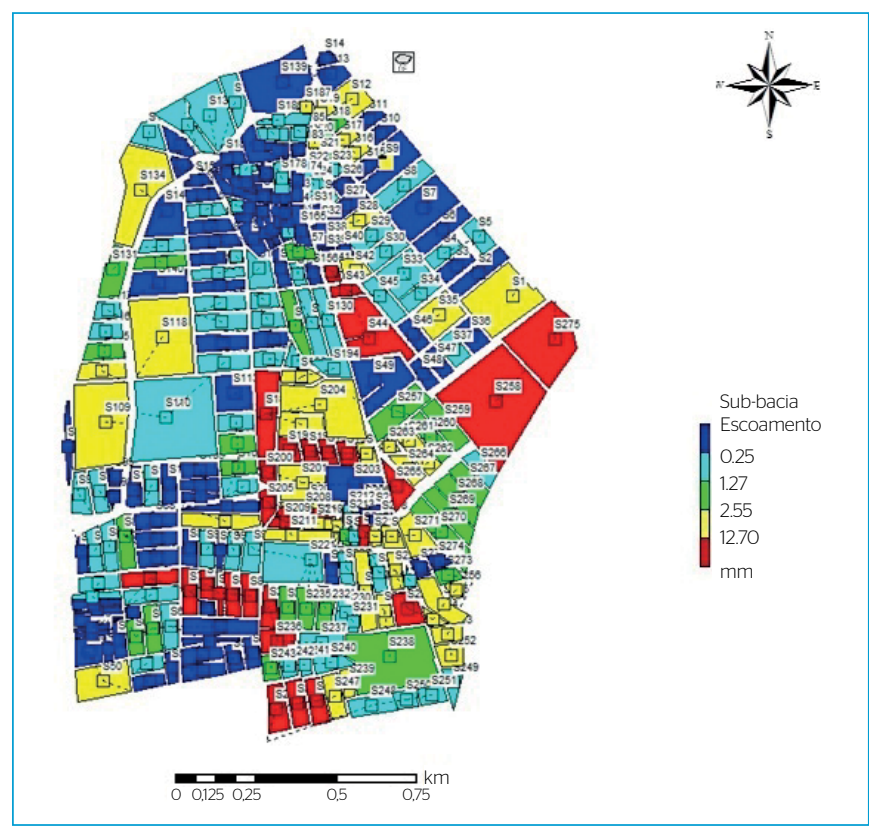

Figura 10 - Mapa de inundação para intensidade de chuva de 40,00mm/h, 60 minutos após a ocorrência de chuva.

Tabela 6 - Taxas de Ocupação e Índices de Aproveitamento segundo Código de Obras.

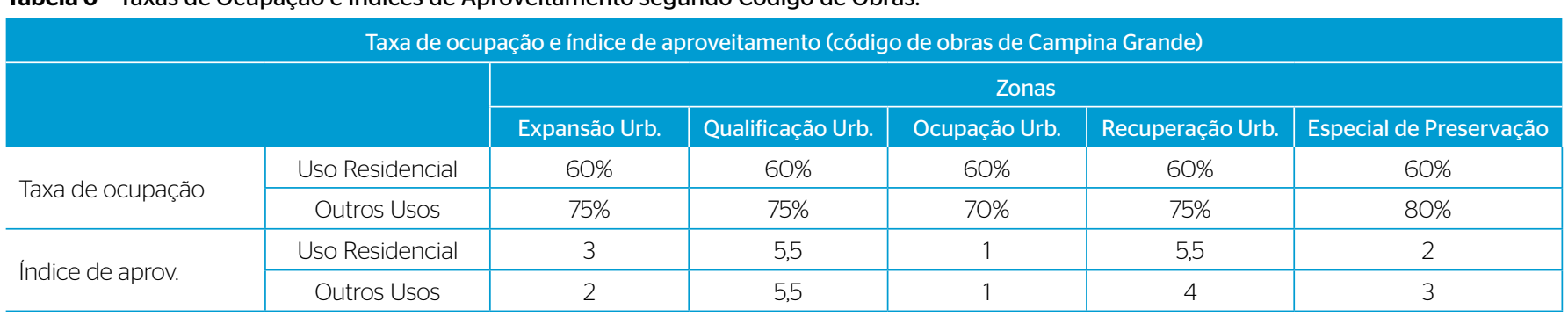

Fonte: adaptado de Estado da Paraíba (2013). 


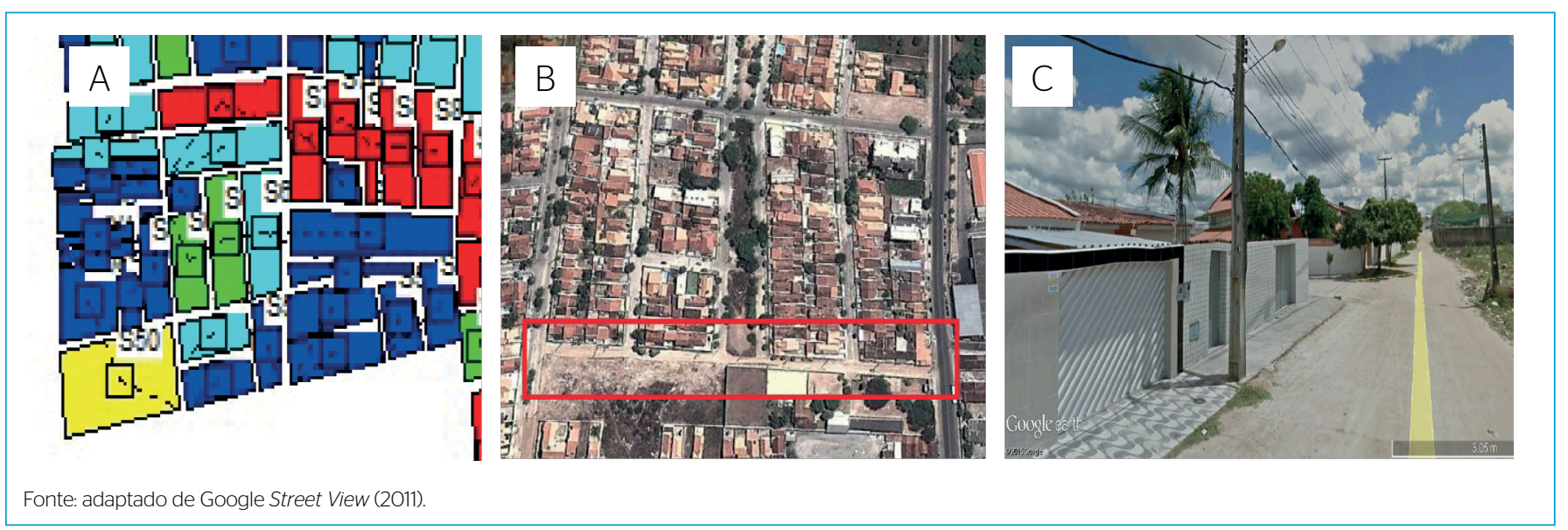

Figura 11 - A) Representação no SWMM de área alagada no bairro do Catolé; B) Vista aérea da área; C) Trecho não pavimentado correspondente à área de alagamento no bairro do Catolé.

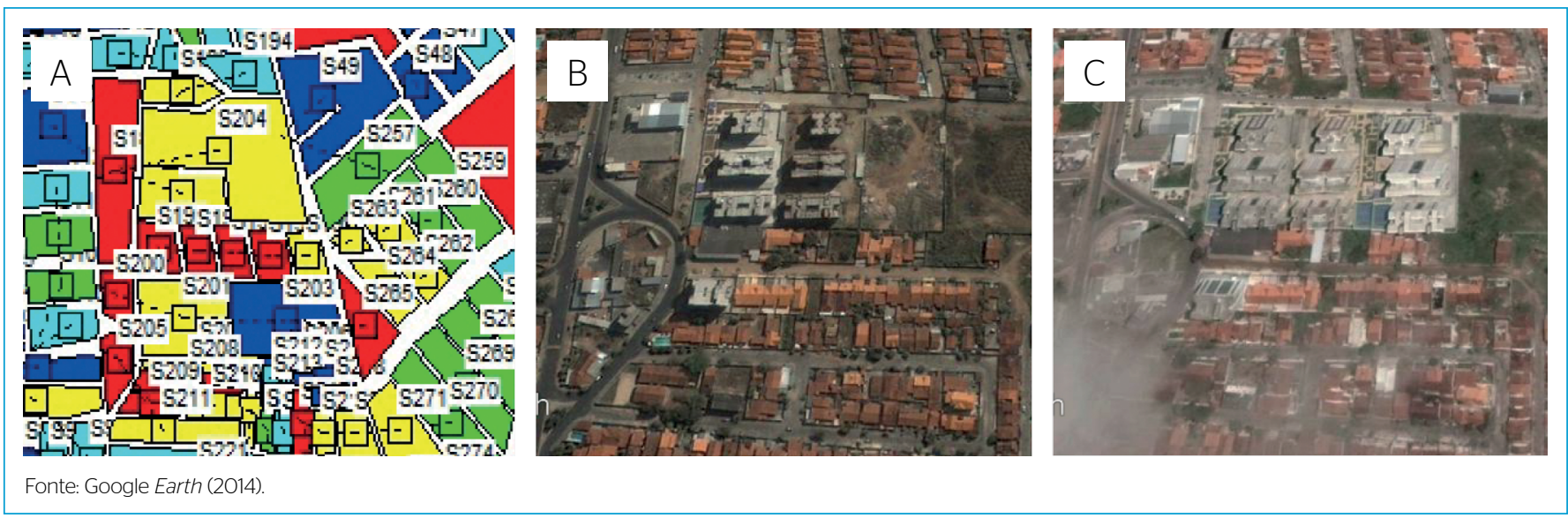

Figura 12 - A) Trecho susceptível a alagamento no bairro Sandra Cavalcante; B e C) imagens aéreas de área impermeabilizada do bairro Sandra Cavalcante nos anos 2010 e 2014, respectivamente.

Ainda no bairro Sandra Cavalcante, nas outras imagens em destaque (Figura 12B e 12C), verificou-se o aumento da impermeabilização do solo, entre os anos 2010-2014, decorrente da construção de edificações multifamiliares no local.

A Figura 13 confirma a insuficiência do sistema de drenagem citado na Figura 12A. Na ocasião, a Agência Executiva de Gestão das Águas do Estado da Paraíba (AESA) divulgou que, em menos de uma hora, choveu 35,4 milímetros em Campina Grande, representando 36\% da média histórica para o mês de março.

Outros pontos representados, como alagamentos pelos outputs do SWMM, também merecem destaque e devem ser considerados em uma possível mudança na estrutura do sistema de drenagem dos dois bairros. Toda e qualquer intervenção no sistema de drenagem deveria, antes de tudo, adequar-se ao crescimento apresentado ao longo dos anos.

\section{CONCLUSÕES}

No tocante à análise do sistema de microdrenagem, à luz do estudo de ocupação do solo nas sub-bacias dos bairros do Catolé e Sandra Cavalcante, observou-se, por meio dos mapas de inundação, que a impermeabilização do solo contribuiu para o aumento do escoamento superficial em decorrência da sobrecarga no sistema de microdrenagem, apesar de o mesmo ter uma capacidade de suporte comprovada.

Mesmo existindo uma legislação que orienta as zonas de ocupação e suas respectivas taxas, a ausência de planejamento na ocupação do solo nos bairros Catolé e Sandra Cavalcante coopera para um alto percentual de área impermeabilizada nos mesmos, acarretando em maior escoamento superficial em períodos de chuva.

Foi constatada a necessidade de uma revisão no sistema de microdrenagem junto às manutenções preventivas do mesmo, para diminuir a ocorrência de alagamentos nos bairros estudados. 

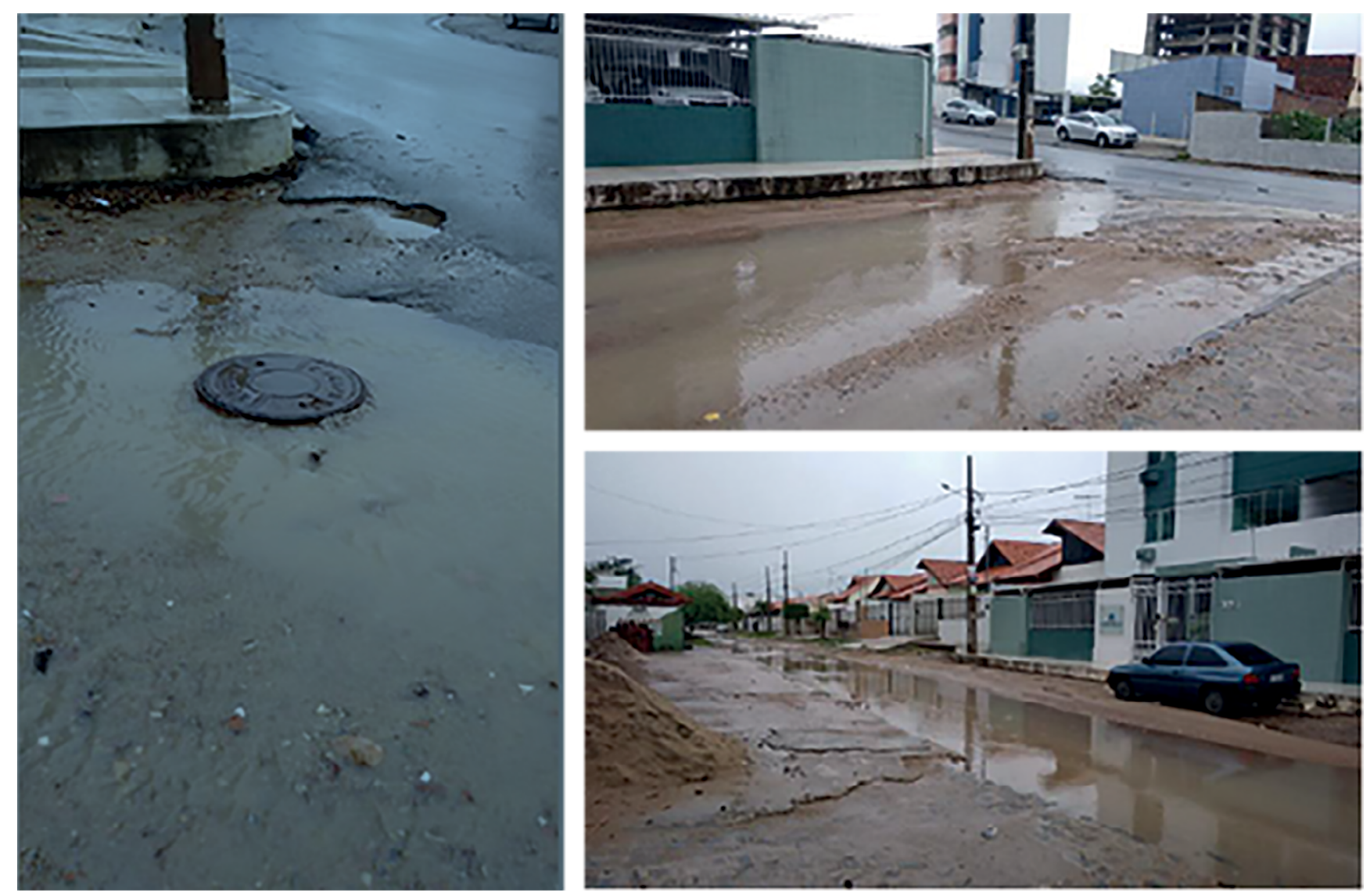

Fonte: arquivo pessoal, 06/03/15.

Figura 13 - Imagem de trecho alagado no bairro Sandra Cavalcante após evento chuvoso do dia 05 de março de 2015.

\section{REFERENCIAS}

ACIOLY, C. \& DAVIDSON, F. (2011) Densidade urbana: um instrumento de planejamento e gestão urbana. 2. ed. Rio de Janeiro: Mauad.

ALENCAR, I. (2014) CG tem 41 pontos de alagamentos. Jornal da Paraíba, Campina Grande. Disponível em: <http://www. jornaldaparaiba.com.br/noticia/120676_cg-tem-41-pontos-dealagamento>. Acesso em: 20 ago. 2014.

ALMEIDA, C.M. (2003) Modelagem da dinâmica espacial como uma ferramenta auxiliar ao planejamento: simulação de mudanças de uso da terra em áreas urbanas para as cidades de Bauru e Piracicaba (SP). Tese (Doutorado em Sensoriamento Remoto) - Instituto Nacional de Pesquisas Espaciais, São José dos Campos.

ARAÚJO, E.L. (2012) Estimativa e análise do crescimento da demanda de água considerando cenários de uso e ocupação do solo. Dissertação (Mestrado em Engenharia de Recursos Hídricos e Sanitária) - Universidade Federal de Campina Grande, Campina Grande.
BASES CARTOGRÁFICAS. (2010). Rio de Janeiro: IBGE. Disponível em: <ftp://geoftp.ibge.gov.br/organizacao_do_territorio/malhas_territoriais/ malhas_municipais/municipio_2010/pb/>. Acesso em: 17 jan. 2017.

CHOW, V.T. (1959) Open-channel hydraulics. New York: McGraw-Hill. 680p.

COHEN, J. (2006) Social, emotional, ethical and academic education: Creating a climate for learning, participation in democracy and well-being. Harvard Educational Review, v. 76, n. 2, p. 201-237.

ESTADO DA PARAÍBA. (2006) Lei Complementar n.o 3, de 9 de outubro de 2006: promove a revisão do Plano Diretor do Município de Campina Grande. Campina Grande: PMCG.

ESTADO DA PARAÍBA. (2013) Lei n.o 5.410/13, de 23 de dezembro de 2013: Código de Obras - dispõe sobre o disciplinamento geral e específico dos projetos e execuções de obras e instalações de natureza técnica, estrutural e funcional do município de Campina

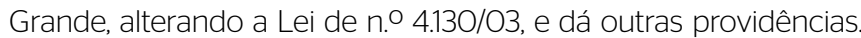
Campina Grande: PMCG. 
ESTIMATIVA DE POPULAÇÃO PUBLICADAS NO D.O.U. (2014) Rio de Janeiro: IBGE. Disponível em: http://www.ibge.gov.br/home/ estatistica/populacao/estimativa2014/estimativa_dou.shtm.

GRANDE, M.; GALVÃO, C:; MIRANDA, L.; RUFINO, I. (2014) Environmental equity as a criterion for water management. Proceedings of ICWRS2014, v. 364, p. 519-525.

KAUFFMANN, M.O. (2003) Expansão urbana e qualidade de vida: proposta para desenvolvimento de indicadores de sustentabilidade aplicados à legislação urbanística. Dissertação (Mestrado em Engenharia Ambiental) - Universidade do Estado do Rio de Janeiro, Rio de Janeiro.

KAUFFMANN, M.O. \& SILVA, L.P. (2005) Taxa de impermeabilização do solo: um recurso para a implementação da bacia hidrográfica como unidade de planejamento urbano integrado à gestão dos recursos hídricos. In: XI Encontro Nacional da Associação Nacional de Pós-Graduação e Pesquisa em Planejamento Urbano e Regional, 11., Salvador. Anais... Salvador.

MARICATO, E. (2003) Metrópole, legislação e desigualdade. Estudos Avançados, v. 17, n. 48, p. 151-167.

NÓBREGA, P.V.M. (2012) Análise do sistema de drenagem de Campina Grande/PB, para proteção de áreas de risco de inundação.
Dissertação (Mestrado em Engenharia de Recursos Hídricos e Sanitária) - Universidade Federal de Campina Grande, Campina Grande.

ROLNIK, R.; KLINTOW, D. (2011) (I)Mobilidade na Cidade de São Paulo. Estudos Avançados, v. 25, n. 71, p. 89-108.

ROSSMAN, L.A. (2010) Epanet 2.O: manual do usuário. Cincinnati: Environmental Protection Agency. Disponivel em: <http://www. lenhs.ct.ufpb.br/?page_id=34>. Acesso em: 15 jul. 2016.

SANTOS, K. A.; RUFINO, I. A. A. (2014) Análise da Permeabilidade do SoloUrbano nos Bairros do CatoléeSandra Cavalcanteem Campina Grande-PB. In: VII Simpósio Regional de Geoprocessamento e Sensoriamento Remoto (Geonordeste), 7., Aracajú. Anais... Aracajú.

SOUZA, M.L. (2009) Mudar a cidade: uma introdução crítica ao planejamento e à gestão urbana. 2. ed. Rio de Janeiro: Bertrand Brasil.

TUCCI, C.E.M. (2008) Águas urbanas. Estudos Avançados, v. 22, n. 63 , p. 97-112.

UN-HABITAT - United Nations Human Settlements Programme. (2004) The state of the world's cities 2004/2005: globalization and urban culture. Nairóbi/Londres: UN-HABITAT/Earthscan. 